\title{
Evidence for Conditional Neuronal Activation following Exposure to a Cocaine-paired Environment: Role of Forebrain Limbic Structures
}

\author{
Erin E. Brown, George S. Robertson, ${ }^{a}$ and Hans C. Fibiger \\ Division of Neurological Sciences, Department of Psychiatry, Faculty of Medicine, University of British Columbia, \\ Vancouver, British Columbia, Canada V6T $1 Z 3$
}

\begin{abstract}
The reinforcing properties of cocaine can readily become associated with salient environmental stimuli that acquire secondary reinforcing properties. This form of classical conditioning is of considerable clinical relevance as intense craving can be evoked by the presentation of stimuli previously associated with the effects of cocaine. To understand better the neurobiology of cocaine-induced environment-specific conditioning, Fos expression was examined in the forebrain of rats exposed to an environment in which they had previously received cocaine. These results were compared to those observed following an acute injection of cocaine.
\end{abstract}

Consistent with its stimulant actions, cocaine produced an increase in locomotion that was accompanied by an increase in Fos expression within specific limbic regions (cingulate cortex, claustrum, piriform cortex, lateral septal nucleus, paraventricular nucleus of the thalamus, lateral habenula, and amygdala) as well as the basal ganglia (dorsomedial striatum and nucleus accumbens). Exposure of rats to the cocaine-paired environment also produced an increase in locomotion, as compared to various control groups. In addition to this behavioral effect, conditioned subjects exhibited a significant increase in Fos expression within the cingulate cortex, claustrum, lateral septal nucleus, paraventricular nucleus of the thalamus, lateral habenula, and the amygdala, suggesting increased neuronal activity within these regions. In contrast to the dramatic effects observed within these structures, no conditional activation was observed within the piriform cortex, nucleus accumbens, or dorsal striatum, suggesting that these brain areas are not involved in the conditioned response.

The present findings indicate that specific limbic regions exhibit increased neuronal activation during the presentation of cocaine-paired cues and may be involved in the formation of associations between cocaine's stimulant actions and the environment in which the drug administration occurred. Although the nucleus accumbens is necessary for the reinforcing and locomotor effects of cocaine, it does not exhibit

\footnotetext{
Received Mar. 17, 1992; revised May 26, 1992; accepted May 28, 1992.

This research was supported by a grant front the Medical Research Council of Canada (PG-23). E.E.B. is supported by a Medical Research Council of Canada studentship. G.S.R. is supported by a postdoctoral fellowship from the Medical Rescarch Council of Canada. The excellent technical assistance of Mark Kimmins is gratefully acknowledged.

Correspondence should be addressed to H. C. Fibiger, Department of Psychiatry, Faculty of Medicine, 2255 Wesbrook Mall, Vancouver, BC V6T 1Z3, Canada.

a Present address: Department of Pharmacology, Faculty of Medicine, University of Ottawa, 451 Smyth Road, Ottawa, Ontario, Canada K1H 8M5

Copyright $(1992$ Society for Neurosciencc $0270-6474 / 92 / 124112-10 \$ 05.00 / 0$
}

a conditional Fos response, suggesting that different neural circuits are involved in the unconditioned and conditioned effects of cocaine.

The classical conditioning of cocaine's behavioral effects with specific environmental stimuli is an important aspect of its actions (Tatum and Seevers, 1929; Barr et al., 1983; Stewart et al., 1984). This property of cocaine is of major significance with respect to its abuse potential, as intense craving can be evoked by stimuli previously associated with the act of taking the drug (Johanson and Fischman, 1989; Gawin, 1991). The magnitude of these conditioned cravings can be overwhelming, and can result in previously abstinent abusers resuming the use of cocaine. It seems likely, therefore, that a better understanding of the neurobiology of this phenomenon will assist in the development of more rational treatments for cocaine abuse.

Given the large body of evidence implicating the mesolimbic dopamine system in the reinforcing properties of drugs of abuse (Roberts et al., 1977, 1989; Lyness et al., 1979; Fibiger and Phillips, 1987; Di Chiara and Imperato, 1988), it is possible that conditioned stimuli associated with drug administration may also produce increases in dopaminergic transmission (Stewart et al., 1984). However, recent data from this laboratory failed to provide evidence for this hypothesis (Brown and Fibiger, 1992). Specifically, the presentation of an environment that had been repeatedly paired with cocaine administration did not produce an increase in interstitial dopamine concentrations in the nucleus accumbens that was significantly greater than that observed in pseudoconditioned controls. This negative neurochemical finding was sharply contrasted by the significantly greater amount of locomotor behavior exhibited by the conditioned subjects. Previous investigators have also reported an absence of evidence for conditioned dopaminergic activity following conditioning with a variety of agents such as cocaine (Barr et al., 1983), fentanyl (Finlay et al., 1988), morphine (Walter and Kuschinsky, 1989), and apomorphine (Möller et al., 1987). Although the findings of these studies indicated an absence of conditional dopamine release, all found significant conditioned behavioral changes.

Recent studies have demonstrated that cocaine increases neuronal expression of Fos, the product of the proto-oncogene $c$-fos, within the striatum and nucleus accumbens (Graybiel et al., 1990; Young et al., 1991), in agreement with the importance of these structures in many of the behavioral properties of cocaine. The transient expression of Fos in response to a variety of physiological and pharmacological manipulations suggests that $c$-fos induction may be used as a marker of neuronal activation (Dragunow and Robertson, 1987; Hunt et al., 1987; Robertson et 
al., 1989, 1991; Rusak et al., 1990; Morgan and Curran, 1989; Fu and Beckstead, 1992). It has therefore been proposed that Fos immunohistochemistry might be utilized as a cellular metabolic marker, similar to 2-deoxyglucose (Hunt et al., 1987; Sagar et al., 1988; Dragunow and Faull, 1989; Morgan and Curran, 1989). Given the ability of cocaine to increase Fos expression and the proposed use of this proto-oncogene product as a marker of neuronal activation, the present study utilized Fos immunohistochemistry to determine if environmental stimuli paired with cocaine administration produce increases in Fos expression in the basal ganglia and various limbic regions.

\section{Materials and Methods}

Subjects and drugs. Subjects were 28 male Long Evans rats (Charles River, Quebec, Canada), weighing 300-400 gm at the beginning of the experiments. The rats were group housed (three per cage), on a $12 \mathrm{hr} /$ $12 \mathrm{hr}$ light/dark cycle (lights on 08:00), with food and water available ad libitum. All subjects were handled periodically for 1 week prior to the experiments. All experimental procedures were conducted at approximately the same time each day, during the animals' light phase.

Both cocaine hydrochloride $(10 \mathrm{mg} / \mathrm{kg}$, dissolved in isotonic saline, $\mathrm{BDH}$ ) and $0.9 \%$ saline were injected intraperitoneally in a volume of $1 \mathrm{ml} / \mathrm{kg}$. The dose of cocaine is expressed as the weight of the salt.

Apparatus and behavioral procedure. Four circular $(61 \mathrm{~cm}$ diameter) activity cages (BRS/LVE), each transcctcd by six infrarcd bcams, were used to measure locomotor activity. Photocell beam interruptions occurring more than $0.5 \mathrm{sec}$ apart were recorded with a NOVA IV (Data General) minicomputer equipped with MANX (GC Controls) software and interface.

The first experiment involved the characterization of the acute effects of cocaine $(10 \mathrm{mg} / \mathrm{kg})$ and saline on locomotor behavior and Fos expression in the rat forebrain. Rats were randomly assigned to one of the activity cages and habituated for $90 \mathrm{~min}$ on 4 consecutive days. One day following the final habituation period, rats were injected with either cocaine $(n=4)$ or saline $(n=4)$ and immediately placed into the activity cage, and locomotor counts were monitored for $90 \mathrm{~min}$. Following the test session, the subjects were deeply anesthetized with sodium pentobarbital $(100 \mathrm{mg} / \mathrm{kg}$, i.p.) and transcardially perfused with isotonic saline followed by $4 \%$ paraformaldehyde in phosphate-buffered $(0.1 \mathrm{M})$ salinc.

The effect of the presentation of an environment that had previously been paired with cocaine administration on locomotor behavior and Fos expression in the rat forebrain was examined in the second experiment. Rats were randomly assigned to one of three groups: conditioned $(n=7)$, pseudoconditioned $(n=7)$, or control $(n=6)$. Conditioned subjects were injected with cocaine $(10 \mathrm{mg} / \mathrm{kg}$, i.p.) and then placed into one of the circular activity cages for $30 \mathrm{~min}$. After the training session, subjects were returned to their home cages, where they were injected with saline ( $1 \mathrm{ml} / \mathrm{kg}$, i.p.) $4 \mathrm{hr}$ later. Pseudoconditioned rats were exposed to an identical procedure except that the order of administration of cocaine and saline was reversed. Specifically, these subjects were injected with saline prior to being placed in the activity cages and later with cocaine in their home cages. Control subjects were exposed to the same procedure as the other groups, except that they were injected with saline in both environments and never received cocaine. Each subject was assigned to a particular locomotor cage for the duration of the experiment. Training was conducted daily for 10 consecutive days at approximately the same time each day. On the test day ( $48 \mathrm{hr}$ after the final training session), subjects were placed in the locomotor cages (no injection given) and activity was monitored for $90 \mathrm{~min}$. Following the test session, the subjects were deeply anesthetized with sodium pentobarbital $(100 \mathrm{mg} / \mathrm{kg}$, i.p.) and transcardially perfused with isotonic saline followed by $4 \%$ paraformaldehyde in phosphate-buffered $(0.1 \mathrm{M})$ saline.

Fos immunohistochemistry. Following a $24-48 \mathrm{hr}$ postfixative period, $30 \mu \mathrm{m}$ sections were cut from each brain using a Vibratome (Pelco) The sections were washed $(10 \mathrm{~min})$ three times with $0.02 \mathrm{M}$ phosphate buffer $(\mathrm{PB})$ before being incubated in phosphate-buffered $0.3 \%$ hydrogen peroxide for $10 \mathrm{~min}$ to remove endogenous peroxidase activity. Sections were then washed three times in $\mathrm{PB}$ and incubated with the Fos primary antisera (1:2000 dilution; also contained $0.3 \%$ Triton- $X$ and $0.02 \% \mathrm{Na}$ azide in PB) for $48 \mathrm{hr}$. A polyclonal sheep antibody (Cambridge Research Biochemicals, CRB OA-11-823) directed against residues 2-16 of the N-terminal region of the Fos protein was used in the present
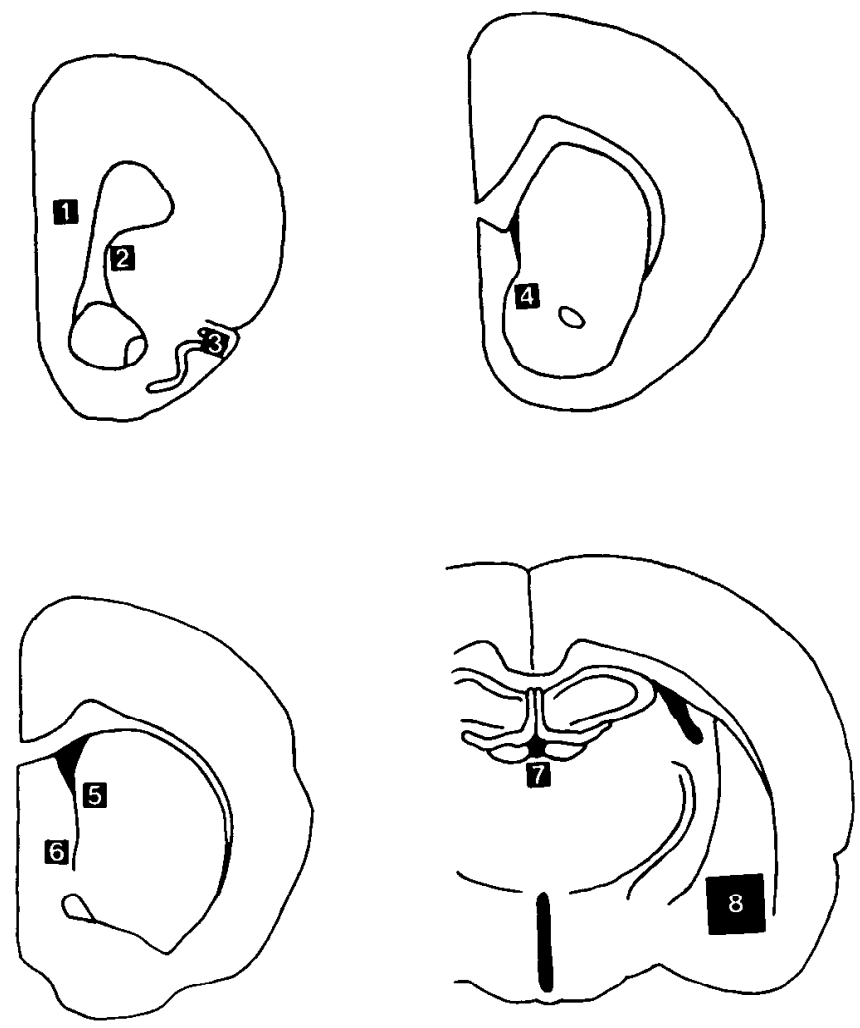

Figure 1. Camera lucida drawings of representative sections used for the counting of Fos-positive nuclei in the cingulate cortex (1), claustrum (2), piriform cortex (3), nucleus accumbens (4), dorsomedial striatum (5), latcral scptum (6), paraventricular nucleus of the thalamus (7), and the amygdala $(8)$. The area of quantification for areas $1-7$ was $510 \times$ $510 \mu \mathrm{m}$. The quantification of the amygdala (8) encompassed a 1290 $\times 1290 \mu \mathrm{m}$ area.

studies. The sections were then washed three times in PB and incubated with a biotinylated rabbit anti-sheep secondary antibody (Vector Laboratories; 1:500 dilution; also contained 0.3\% Triton-X in PB) for $1 \mathrm{hr}$. Sections were washed three times in PB before being incubated with $0.3 \%$ Triton-X and $0.5 \%$ avidin-biotinylated horseradish peroxidase complex (Vector Laboratories) in PB for $1 \mathrm{hr}$. Sections were then washed two times with PB and once with an acetate buffer $(0.1 \mathrm{M}, \mathrm{pH} 6.0)$ before being visualized by the glucose oxidase-diaminobenzidine-nickel method (Shu et al., 1988). The reaction was terminated by washing the sections in acetate buffer $(0.1 \mathrm{M}, \mathrm{pH} 6.0)$. Sections were mounted on chrome-alum-coated slides, dehydrated, and prepared for microscopic examination. A more detailed description of this technique has been published previously (Robertson and Fibiger, 1992). It should be noted that immunoblot analysis (CRB technical data sheet) indicates that the $\mathrm{CRB}$ antibody recognizes Fos $(62 \mathrm{kDa})$ as well as other Fos-related antigens $(48 / 49$ and $70 \mathrm{kDa})$. However, the delayed onset of the Fosrelated antigens (Morgan and Curran, 1989) would suggest that Fos is responsible for the immunoreactivity quantified in the present study. The time chosen for perfusion $(90 \mathrm{~min}$ after the initiation of all experimental manipulations) approximately coincides with the peak levels of Fos antigens (Morgan and Curran, 1989).

Quantification of Fos-positive cells. Fos expression within the cingulate cortex, claustrum, piriform cortex, nucleus accumbens, dorsomedial striatum, lateral septal nucleus, and paraventricular nucleus of the thalamus was quantified by counting the number of Fos-positive nuclei within a $510 \times 510 \mu \mathrm{m}$ grid placed over the area at $107 \times$ magnification. The number of Fos-positive nuclei within the amygdala was also quantified; the grid for these counts was $1290 \times 1290 \mu \mathrm{m}$ at $43 \times$ magnification. Camera lucida drawings illustrate the spccific rcgions sampled and anterior-posterior position of the sections used (Fig. 1). In addition to the aforementioned regions, the number of Fos-positive nuclei within the lateral habenula was also examined. However, due to rostrocaudal variation of the sections available from this region, it was not deemed appropriate to quantify the data in the same manner as was used for 


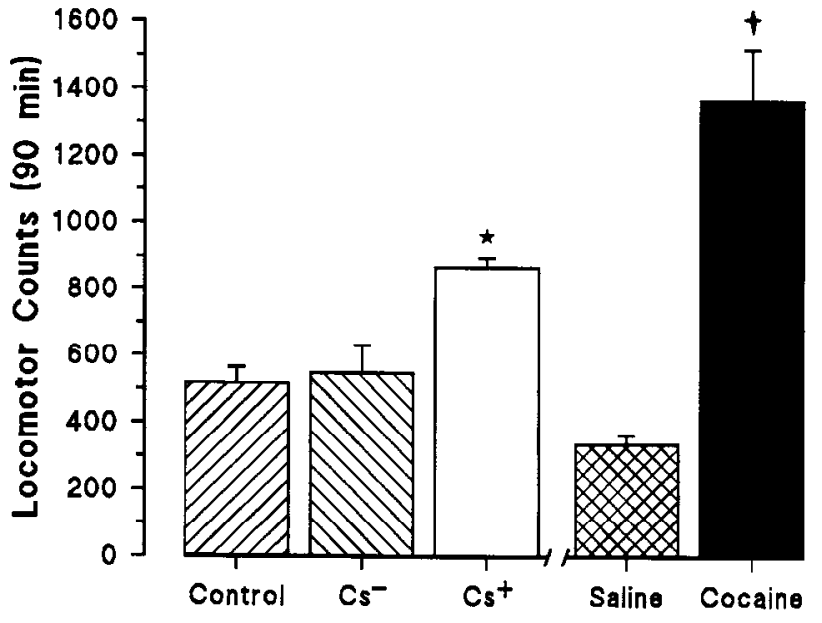

Figure 2. Total number of locomotor counts for control $(n=6)$, pseudoconditioned $\left(\mathrm{Cs}^{-} ; n=7\right)$, and conditioned $\left(\mathrm{Cs}^{+} ; n=7\right)$ subjects following $10 \mathrm{~d}$ of conditioning with cocaine $(10 \mathrm{mg} / \mathrm{kg}$, i.p.). Testing occurred $48 \mathrm{hr}$ after the last training session, and was conducted in the same apparatus used for the training procedure. Locomotor counts are also shown for unconditioned subjects that received acute injections of saline $(1 \mathrm{ml} / \mathrm{kg} ; n=4)$ or cocaine $(10 \mathrm{mg} / \mathrm{kg} ; n=4)$. Values represent the group mean $\perp$ SEM. $*, P<0.005$ compared to pseudoconditioned controls. $\dagger, P<0.005$ compared to saline-treated controls.
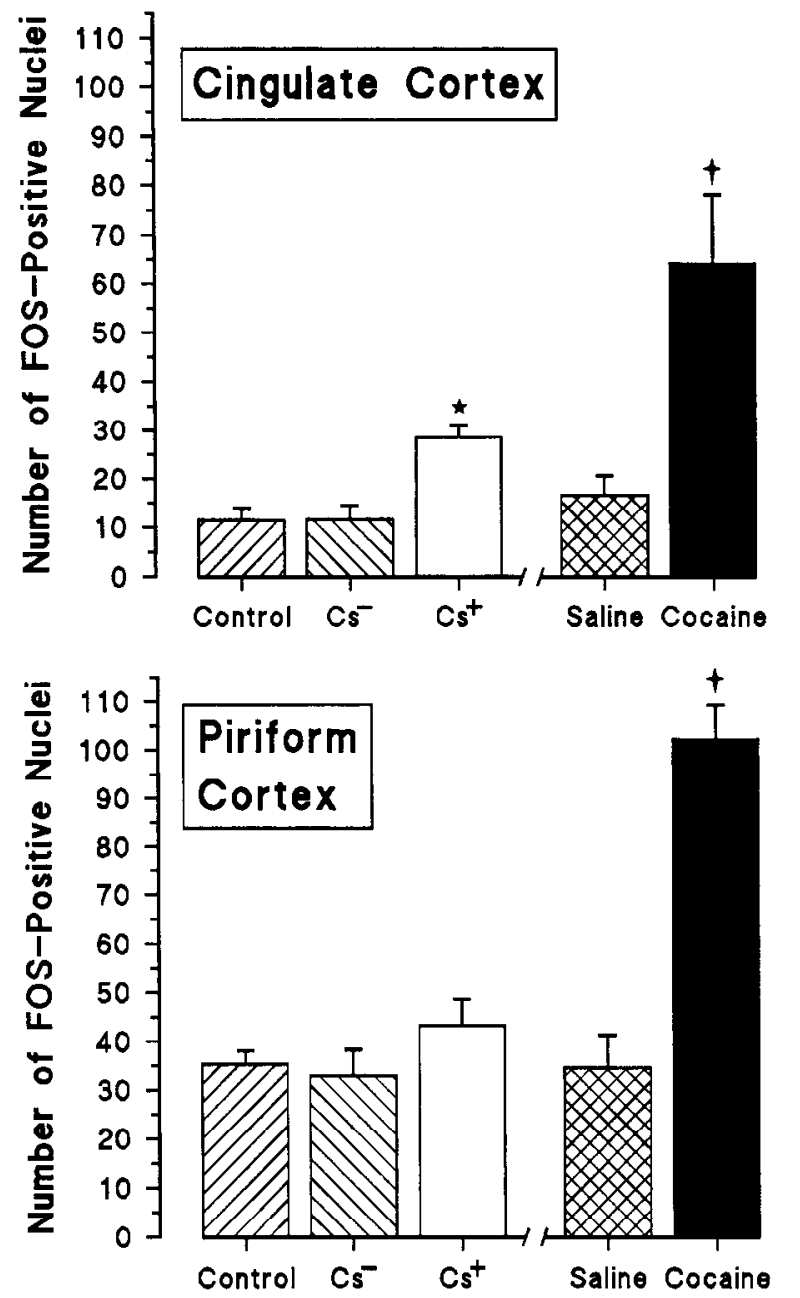

the other regions. To increase the reliability of the quantification, cell counts were made from two separate sections of each region from a given subject. In addition, duplicate counts of cach scction wcre conducted by two independent observers. This procedure therefore resulted in a total of four determinations of the number of Fos-positive nuclei within a specified region for each subject. The average of these four determinations was utilized for the subsequent statistical analysis.

Statistical analysis. Between-group differences in locomotor counts and the number of Fos-positive nuclei within specified regions from the conditioning experiment subjects were evaluated using univariate analyses of variance. Post hoc comparisons between control, pseudoconditioned, and conditioned subjects were conducted using Tukey's honestly significant difference test. Univariate analyses of variance were also conducted to assess locomotor differences and the number of Fospositive nuclei within specified regions between acute saline- and cocaine-treated subjects.

\section{Results}

The brain areas quantified in the present study reflect those areas that were determined to have positive responses to the acute administration of cocaine or the presentation of the cocaine-paired environment. These initial observations were performed by a "blind" observer who scanned coronal sections throughout the forebrain to determine regions that exhibited increased Fos immunoreactivity. No other forebrain regions exhibited reliable responses to the present treatments.

As expected, compared to saline treated controls the acute
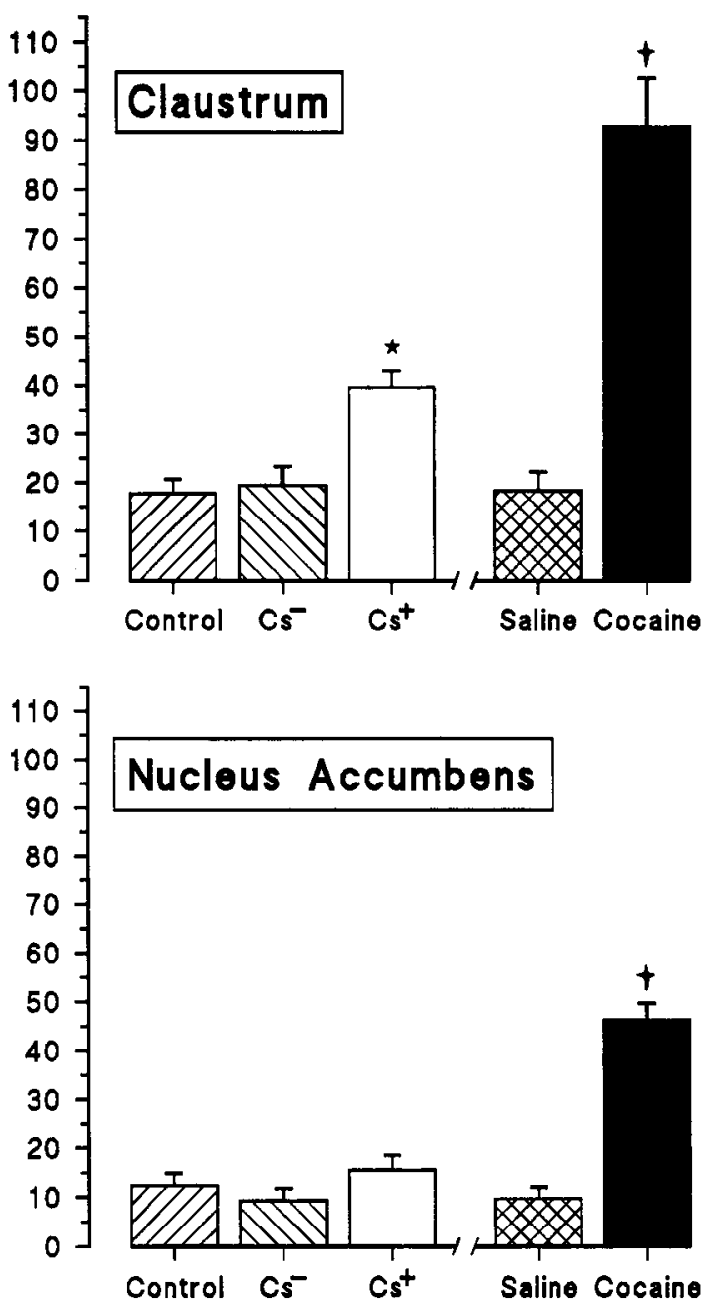

Figure 3. Number of Fos-positive nuclei within a $510 \times 510 \mu \mathrm{m}$ area in the cingulate cortex, claustrum, piriform cortex, and nucleus accumbens for control $(n=6)$, pseudoconditioned $\left(C s^{-} ; n=7\right)$, conditioned $\left(C s^{+} ; n=7\right)$, saline-treated $(n=4)$, and cocaine-treated $(n=4)$ subjects. Values represent the group mean \pm SEM. ${ }^{*}, P<0.05$ compared to pseudoconditioned controls. $\dagger, P<0.05$ compared to saline-treated controls. 

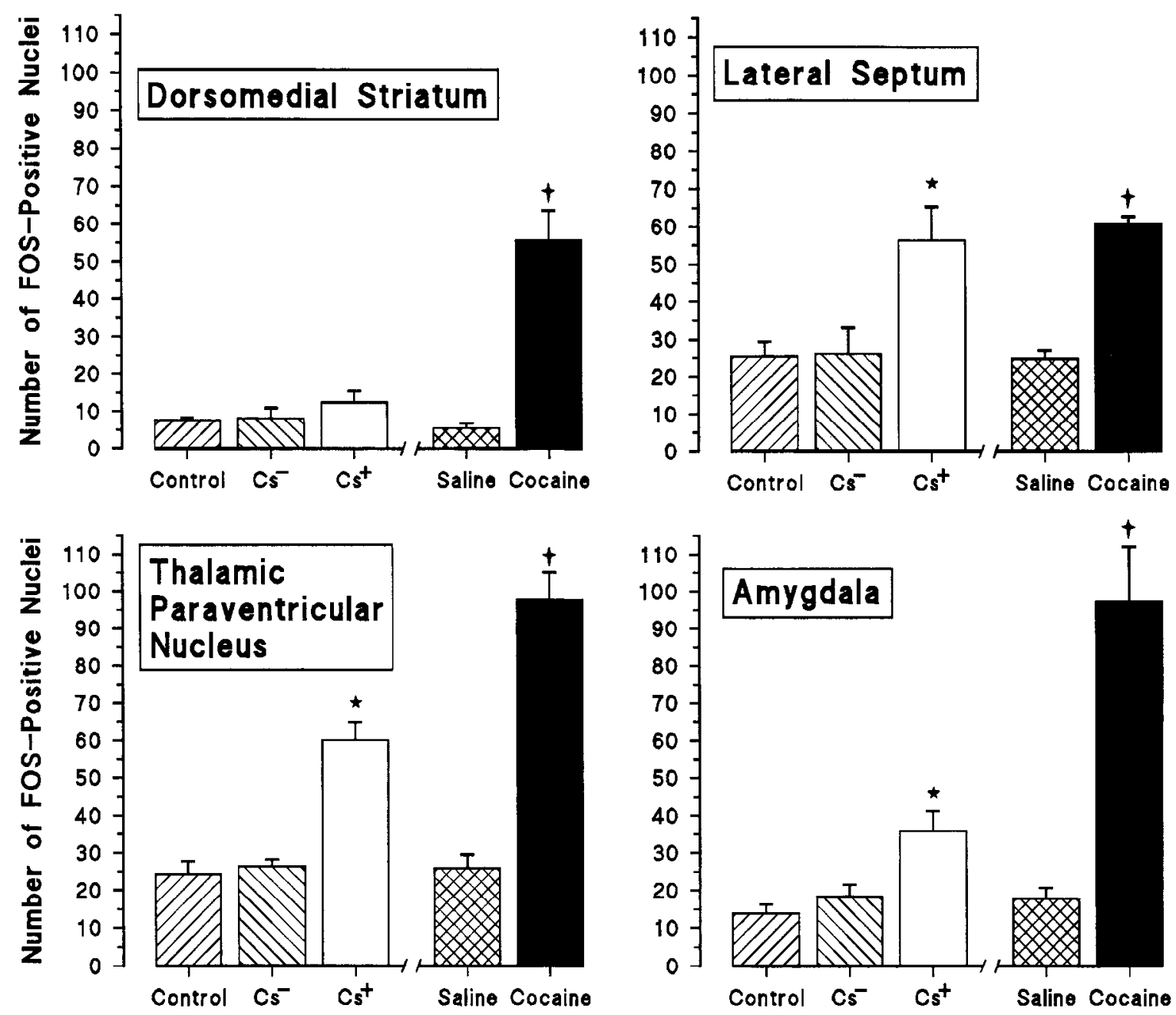

Figure 4. Number of Fos-positive nuclei within a $510 \times 510 \mu \mathrm{m}$ area in the dorsomedial striatum, lateral septum, and paraventricular nucleus of the thalamus and within a $1290 \times 1290 \mu \mathrm{m}$ area in the amygdala for control $(n=6)$, pseudoconditioned $\left(C s^{-} ; n=7\right)$, conditioned $\left(C s^{+} ; n=\right.$ $7)$, saline-treated $(n=4)$, and cocaine-treated $(n=4)$ subjects. Values represent the group mean \pm SEM. ${ }^{*}, P<0.05$ compared to pseudoconditioned controls. $\dagger, P<0.05$ compared to saline-treated controls.

administration of cocaine produced a significant increase in locomotor counts $[F(1,6)=45.42 ; p<0.005$; Fig. 2]. This behavioral effect was accompanied by significant increases in the number of Fos-positive nuclei in the cingulate cortex $[F(1,6)=$ $10.69 ; p<0.05]$, claustrum $[F(1,6)=50.26 ; p<0.001]$, piriform cortex $[F(1,6)=49.98 ; p<0.001]$, nucleus accumbens $[F(1,6)$ $=82.81 ; p<0.001]$, dorsomedial striatum $[F(1,6)=40.83 ; p$ $<0.005]$, lateral septum $[F(1,6)=134.32 ; p<0.001]$, paraventricular nucleus of the thalamus $[F(1,6)=80.46 ; p<0.001]$, and amygdala $[F(1,6)=28.3 ; p<0.005]$, as compared to salinetreated controls (Figs. 3-6).

The conditioning procedure employed in the present study produced a clear conditional behavioral effect $[F(2,17)=10.35$; $p<0.005$; Fig. 2]. Post hoc comparisons demonstrated that conditioned subjects exhibited significantly more locomotor counts than either control or pseudoconditioned controls $(p<$ 0.05 ). This conditioned effect stands in contrast to the lack of a significant group difference between the pseudoconditioned and control subjects (Fig. 2).

In addition to producing a significant behavioral effect, the conditioning procedure resulted in increased Fos expression within specific brain regions (Figs. 3-6). Significant group effects were observed for the cingulate cortex $[F(2,17)=14.19 ; p<$
$0.0005]$, claustrum $[F(2,17)=12.56 ; p<0.0005]$, lateral septal nucleus $[F(2,17)=6.05 ; p<0.02]$, paraventricular nucleus of the thalamus $[F(2,17)=32.12 ; p<0.0001]$, and amygdala $[F(2,17)=8.33 ; p<0.005]$. Post hoc comparisons revealed that conditioned subjects exhibited significantly more Fos-positive nuclei than control or pseudoconditioned subjects in the cingulate cortex, claustrum, lateral septal nucleus, paraventricular nucleus of the thalamus, and amygdala $(p<0.05)$, while no differences were observed between control and pseudoconditioned subjects (Figs. 3, 4). In contrast, the number of Fospositive nuclei within the nucleus accumbens $[F(2,17)=1.51]$, dorsomedial striatum $[F(2,17)=1.04]$, and piriform cortex $[F(2,17)=1.29]$ did not differ significantly between the control, pseudoconditioned, or conditioned subjects.

Although the conditioned subjects exhibited an enhanced locomotor response, the magnitude of this effect was considerably less than that observed following an acute injection of cocaine $[F(1,9)=18.68 ; p<0.005$; Fig. 2]. In accordance with this behavioral difference, conditioned subjects exhibited significantly fewer Fos-positive nuclei than animals treated acutely with cocaine in the cingulate cortex $[F(1,11)=11.29 ; p<0.01]$, claustrum $[F(1,11)=40.45 ; p<0.001]$, piriform cortex $[F(1,11)$ $=46.38 ; p<0.001]$, nucleus accumbens $[F(1,11)=44.89 ; p<$ 

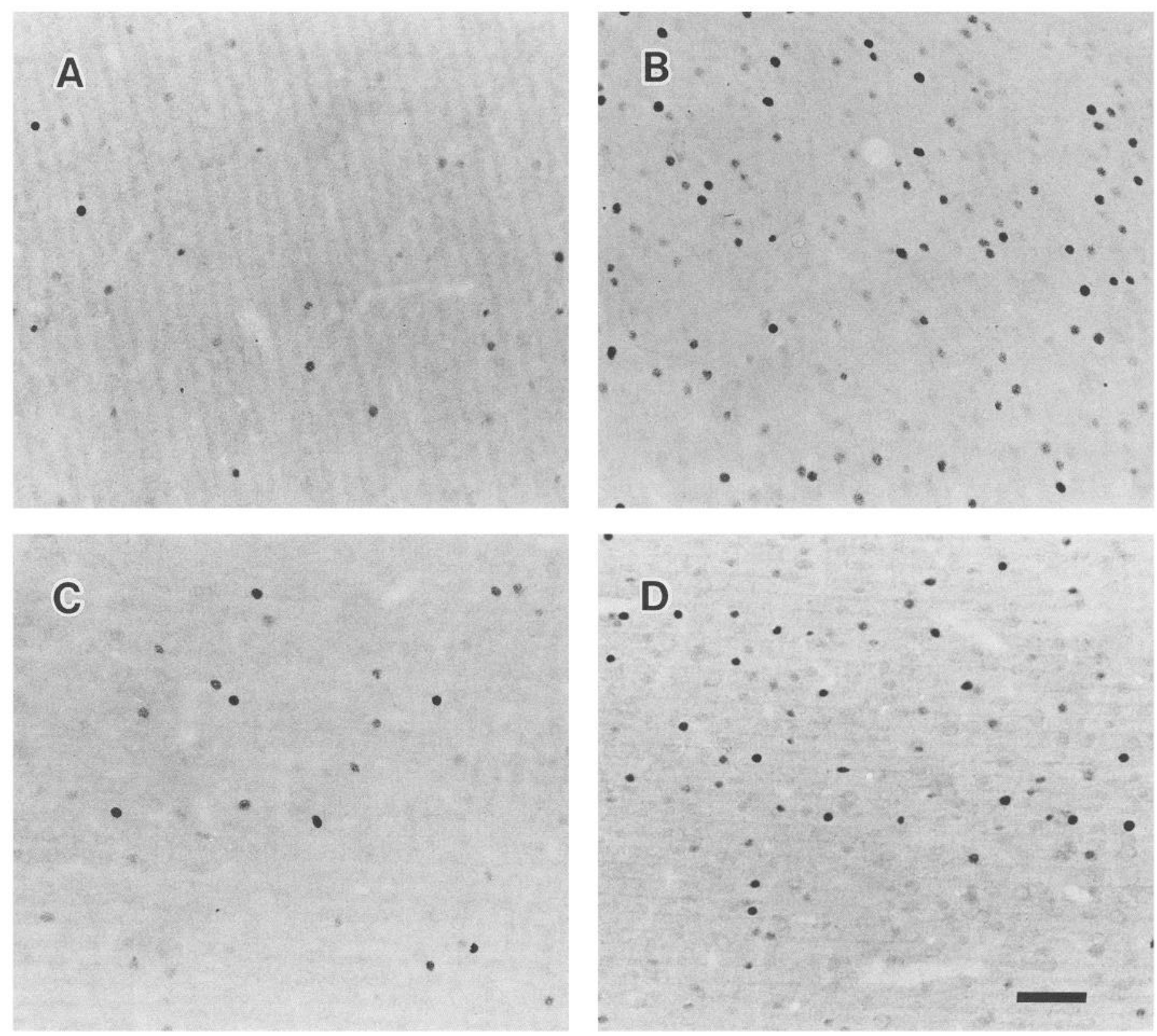

Figure 5. Photomicrographs of Fos immunoreactivity in the cingulate cortex from representative saline-treated $(A)$ and cocaine-treated $(B)$ subjects, as well as pseudoconditioned $(C)$ and conditioned $(D)$ subjects. Scale bar, $100 \mu \mathrm{m}$.

$0.001]$, dorsomedial striatum $[F(1,11)=37.82 ; p<0.001]$, paraventricular nucleus of the thalamus $[F(1,11)=20.61 ; p<$ $0.005]$, and amygdala $[F(1,11)=22.66 ; p<0.005$; Figs. 3, 4]. Interestingly, the number of Fos-positive nuclei within the lateral septal nucleus was equivalent between the conditioned and cocaine-treated subjects $[F(1,11)=0.13$; Fig. 4].

It is noteworthy that the numbers of Fos-positive nuclei within the cingulate cortex $[F(1,8)=1.23]$, claustrum $[F(1,8)=0.02]$, piriform cortex $[F(1,8)=0.01]$, nucleus accumbens $[F(1,8)=$ $0.58]$, dorsomedial striatum $[F(1,8)=2.89]$, lateral septal nucleus $[F(1,8)=0.01]$, paraventricular nucleus of the thalamus $[F(1,8)=0.08]$, or amygdala $[F(1,8)=1.08]$ were not significantly different between control subjects from the conditioning experiment and subjects acutely injected with saline (Figs. 3, 4).

In addition to the aforementioned regions, compared to saline-treated controls cocaine produced an increase in the number of Fos-positive nuclei in the medial portion of the lateral habenula (Fig. 6). Conditioned subjects also exhibited a large and robust increase in Fos expression within this area, while virtually no Fos-positive nuclei were observed within this region of the pseudoconditioned controls. Due to variations in the anteriorposterior coordinates of the sections obtained from this region, reliable quantification was not possible. However, all of the acute cocaine and conditioned subjects that were examined displayed reliable increases in Fos expression, while none of the control, pseudoconditioned, or saline-treated subjects exhibited substantial Fos expression in this structure.

\section{Discussion}

In agreement with earlier studies (Graybiel et al., 1990; Young et al., 1991), acute administration of cocaine elevated Fos immunoreactivity in the striatum and nucleus accumbens. In ad- 

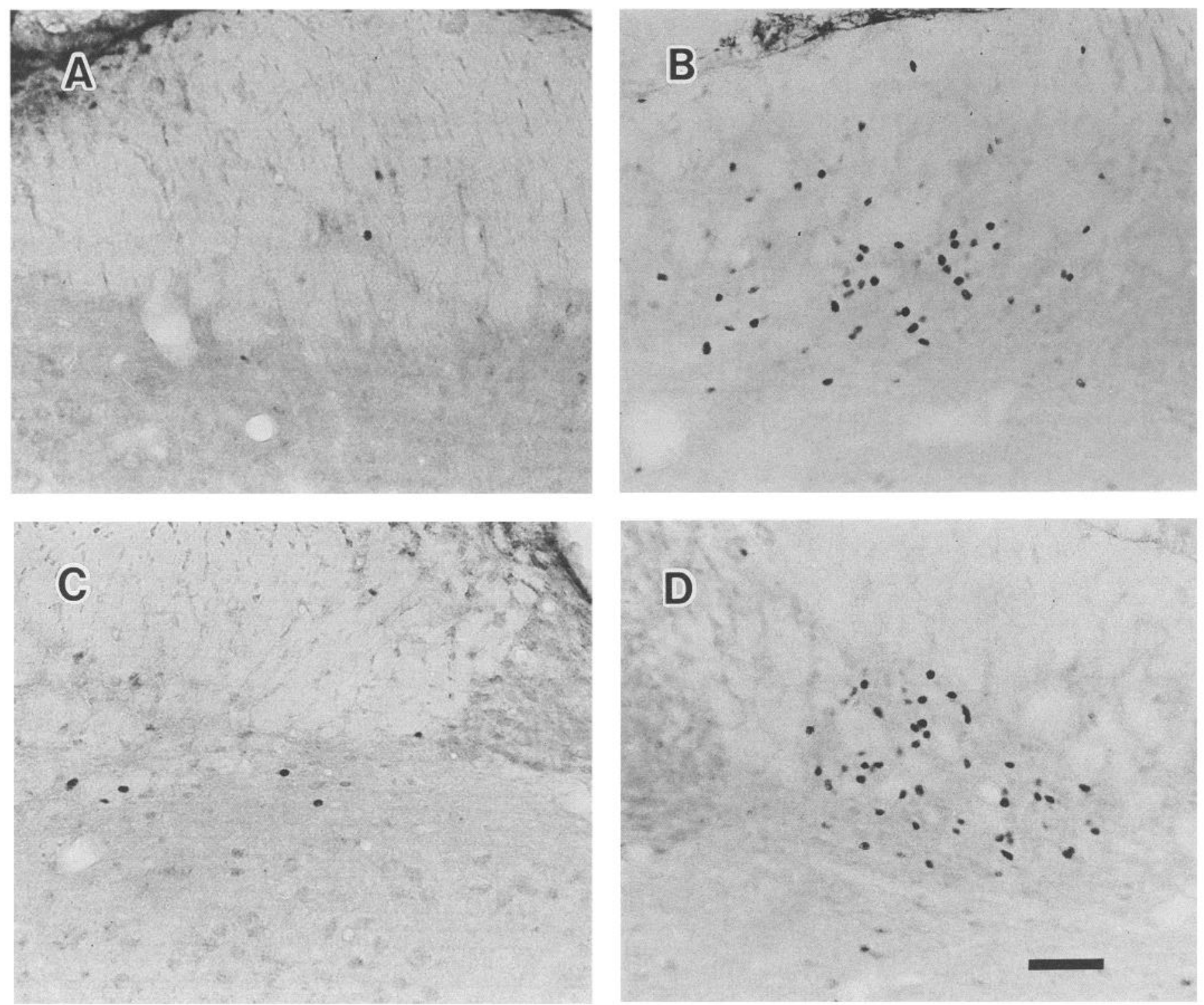

Figure 6. Photomicrographs of Fos immunoreactivity in the lateral habenula from representative saline-treated $(A)$ and cocaine-treated $(B)$ subjects, as well as pseudoconditioned $(C)$ and conditioned $(D)$ subjects. Scale bar, $100 \mu \mathrm{m}$.

dition, cocaine enhanced Fos immunoreactivity in the cingulate cortex, claustrum, piriform cortex, lateral septal nucleus, paraventricular nucleus of the thalamus, medial portion of the lateral habenula, and amygdala. The results of the second experiment confirmed that the unconditioned locomotor stimulatory effects of cocaine can be classically conditioned to environmental stimuli (Tatum and Seevers, 1929; Barr et al., 1983; Beninger and Herz, 1986). Moreover, this conditioning was accompanied by changes in Fos immunoreactivity within specific limbic regions, suggesting a conditional increase in neuronal activity within these areas and that these limbic regions are involved in mediating the conditioned behavior.

The ability of cocaine to increase Fos expression in the striatum and nucleus accumbens is thought to be mediated through the activation of $D_{1}$ dopamine receptors (Graybiel et al., 1990; Young et al., 1991). This finding is in agreement with the ability of cocaine to increase dopaminergic transmission (Di Chiara and Imperato, 1988; Kalivas and Duffy, 1990; Brown et al.,
1991; Pettit and Justice, 1991) and the heavy dopaminergic innervation of the nucleus accumbens and striatum (Björklund and Lindvall, 1984). The present results illustrate that cocaine also produces increases in Fos in the cingulate cortex, claustrum, piriform cortex, lateral septal nucleus, paraventricular nucleus of the thalamus, medial portion of the lateral habenula, and amygdala. Although each of these structures receives at least a modest dopaminergic innervation (Björklund and Lindvall, 1984), it is possible that the increase in Fos-positive nuclei within some or all of these regions is not dopaminergically mediated. Specifically, cocaine blocks the uptake of noradrenaline and 5-HT, in addition to its well-studied actions on dopamine (Richelson and Pfenning, 1984; Ritz et al., 1987). Furthermore, the presence of noradrenergic and serotonergic projections to many of these areas precludes the assumption that the observed effects were dopaminergically mediated (Moore and Card, 1984; Steinbusch, 1984). It is noteworthy that a recent study has provided evidence that clozapine-induced increases in Fos expres- 
sion within the nucleus accumbens are dopamine dependent while increases in the cingulate cortex and lateral septum are not (Robertson and Fibiger, 1992). Finally, it is also possible that cocaine-induced activation of Fos expression in some areas was one or more synapses "downstream" from one of the primary sites of action of cocaine. Studies utilizing selective neurotoxins and receptor antagonists would help elucidate the neurotransmitter(s) involved in the cocaine-induced increases in Fos expression within these limbic regions.

In agreement with previous studies, the results from the second experiment demonstrate that the behavioral effects of cocaine can be classically conditioned to environmental stimuli (Tatum and Seevers, 1929; Barr et al., 1983; Beninger and Herz, 1986). The classical conditioning of a drug to environmental cues is not unique to cocaine and has been reported with other stimulants, as well as with opiates (Beninger and Hahn, 1983; Stewart et al., 1984; Möller et al., 1987; Walter and Kuschinsky, 1989). The clinical significance of this drug-environment conditioning is considerable, as conditioned cues can evoke intense cravings, which play a substantial role in the relapse into cocaine use (Gawin, 1991).

Cocaine-induced conditioned locomotion was accompanied by a conditional increase in Fos expression within specific limbic nuclei. Given the proposed use of Fos immunohistochemistry to map functional pathways in the brain (Hunt et al., 1987; Sagar et al., 1988; Dragunow and Faull, 1989; Morgan and Curran, 1989) and the ability of various behavioral and physiological manipulations to increase $c$-fos expression in the CNS (Hunt et al., 1987; Rusak et al., 1990; Campeau et al., 1991; Chastrette et al., 1991; Sharp et al., 1991), the present findings may reflect at least a portion of the nuclei and regions involved in the conditioned response. It is noteworthy that a recent report has also demonstrated a conditioned activation of $c$-fos. Campeau et al. (1991) have reported that conditioned fear produces dramatic increases in $c$-fos expression within the amygdala, a result supported by previous electrophysiological findings (Applegate et al., 1982; Pascoe and Kapp, 1985).

The claustrum or orbitofrontal arca and the cingulate cortex, both components of the prefrontal cortex (Groenewegen, 1988), exhibited an increase in Fos expression in conditioned subjects when they were exposed to the environment in which they had previously received cocaine. This finding is fully compatible with previous electrophysiological and lesion studies that demonstrate the importance of the cingulate cortex in classical conditioning (Gabriel et al., 1980; Buchanan and Powell, 1982; Gabriel and Sparenborg, 1987; Powell et al., 1990). Moreover, the diverse afferent connections of the prefrontal cortex from limbic as well as sensory areas allow for the potential integration of multimodal sensory information necessary to produce the associations involved in conditioning (Groenewegen et al., 1990; Lopez da Silva et al., 1990). Although both the acute administration of cocaine and the presentation of the cocaine-paired environment produced increases in Fos-positive nuclei in the claustrum and cingulate cortex, it is not possible to ascertain if these different treatments produce their effects by the activation of the same afferent projections.

Conditional Fos expression was also observed in the lateral septal nucleus. Interestingly, this was the only area examined where the magnitude of the conditioned response was equivalent to the acute drug effect (Fig. 4). This unique response may suggest a primary role for the lateral septum in the conditioned behavior. With afferents from the amygdala, ventral tegmental area, and hippocampus and major efferent pathways to the mammillary bodies, lateral hypothalamus, and medial septum, the lateral septum exhibits connectivity that is consistent with its rolc in the formation of associations between affective states and environmental stimuli (Raisman, 1966; Krettek and Price, 1978; Swanson and Cowan, 1979). Consistent with this proposal, electrophysiological studies have demonstrated that the activity of neurons in the lateral septal nucleus is sensitive to the presentation of conditioned stimuli (Thomas and Yadin, 1980; Thomas, 1988; Thomas et al., 1991). Based on these and other findings, it has been hypothesized that the lateral septum is involved in the inhibition of aversive affective states (Thomas, 1988). In view of the present findings, future examination of the potential role of this structure in appetitive classical conditioning is warranted.

Given the large body of data suggesting that various amygdaloid nuclei participate in Pavlovian conditioning (Kapp et al., 1981; Miskin and Aggleton, 1981; Applegate et al., 1982; Pascoe and Kapp, 1985; Dunn and Everitt, 1988; Roozendaal et al., 1990), it is not surprising that a conditional increase in Fospositive nuclei was observed within this structure in the present study. These data are also consistent with the proposed role of the amygdala in the development of stimulus-reward associations, as demonstrated in a variety of experimental paradigms (Cador et al., 1989; Robbins et al., 1989; Everitt et al., 1991; Hiroi and White, 1991). Furthermore, Post et al. (1988) have reported that although lesions of the amygdala (electrolytic and 6-hydroxydopamine) did not affect cocaine-induced hyperactivity, they greatly attenuatcd environment-specific cocainc sensitization. Given these previous findings, the present results are fully consistent with the proposed role of the amygdala in conditioning in general, and in stimulus-reward associations in particular.

One shortcoming of the present data is that Fos immunoreactivity was not localized to specific amygdaloid nuclei. Although the area of quantification was centered around the central and basolateral nuclei, the present histological material was not suitable for the unequivocal delineation of the boundaries of the amygdaloid nuclei. Given the anatomical and physiological diversity of the specific amygdaloid nuclei, future studies should examine the role of particular nuclei.

Two additional areas that exhibited a conditional increase in Fos immunoreactivity were the lateral habenula and the paraventricular nucleus of the thalamus. Although the absence of quantifiable data precludes any strong conclusions being put forward regarding the effect observed in the lateral habenula, it is noteworthy that it has recently been reported that the medial portion of the lateral habenula exhibits an increase in Fos immunoreactivity in response to restraint stress (Chastrette et al., 1991). Interestingly, the distribution of Fos-positive nuclei observed in this study (Fig. 6) and that of Chastrette et al. (1991) corresponds to the dopaminergic innervation of the lateral habenula (Phillipson and Pycock, 1982). Given the proposed role of this nucleus in a fecdback loop from the frontal cortex to the ventral tegmental area (Lisoprawski et al., 1980; Phillipson and Pycock, 1982) and its purported significance in motivated behavior (Sutherland, 1982), further examination of its role in conditioned behavior is warranted.

A variety of stressors have been shown to increase Fos immunoreactivity in the paraventricular nucleus of the thalamus (Chastrette et al., 1991; Sharp et al., 1991). The present data indicate that this midline thalamic nucleus is also responsive 
to the presentation of an appetitive conditioned stimulus. Although the functional significance of the paraventricular nucleus is unclear, it is apparent that it is not a "nonspecific" nucleus (Bentivoglio et al., 1990). The dopaminergic innervation of the paraventricular nucleus and its dense efferent projections to the amygdala, cingulate cortex, and the nucleus accumbens are consistent with a "limbic" role for this midline thalamic nucleus and are in agreement with its hypothesized role in learning and memory (Bentivoglio et al., 1990).

Although the conditional activation of Fos expression was observed within many of the regions that were affected by acute cocaine, the nucleus accumbens, striatum, and piriform cortex did not exhibit an increased number of Fos-positive nuclei in the conditioned subjects. The absence of conditional Fos expression within the nucleus accumbens supports our previous report that the cocaine-induced conditioned locomotion is not accompanied by an increase in dopamine release in this structure (Brown and Fibiger, 1992). Despite the fact that the nucleus accumbens has been strongly implicated in stimulant-induced locomotor activity (Kelly et al., 1975; Joyce and Koob, 1981; Delfs et al., 1990), dopaminergic projections to other limbic structures may play a critical role in environment-specific conditioned locomotion. This possibility is consistent with the conditional increase in Fos expression in the aforementioned limbic structures, such as the cingulate cortex, lateral septum, and amygdala, that have been demonstrated to participate in classical conditioning and to receive dopaminergic innervation (Björklund and Lindvall, 1984). Although a number of investigators have reported that dopamine receptor antagonists are ineffective in attenuating the conditioned locomotor effects of cocaine and other psychomotor stimulants (Beninger and Hahn, 1983; Beninger and Herz, 1986; Weiss et al., 1989), the antagonists used in these studies are primarily directed against the $\mathrm{D}_{2}$ receptor, leaving the possibility that dopamine could be acting through $D_{1}$ receptors.

Irrespective of the potential dopaminergic involvement in the conditional behavioral effect, the present data indicate that the neurobiological substrates for a conditioned response can differ from those of the unconditioned response. As noted previously, the dopaminergic projection to the nucleus accumbens appears to be necessary for the unconditioned locomotor effects of cocaine (Kelly et al., 1975; Joyce and Koob, 1981; Delfs et al., 1990) and the acute reinforcing effects of cocaine and other psychomotor stimulants (Roberts et al., 1977, 1980; Lyness et al., 1979; Pettit et al., 1984). However, the present findings fail to provide evidence of increased Fos expression in the nucleus accumbens associated with the conditioned response. This absence of effect occurs in spite of the large number of other regions that displayed a conditioned response and the finding that this nucleus exhibits a robust increase in Fos expression in response to cocaine itself. This result is in general agreement with previous neurochemical studies that have reported no evidence for an increase in dopaminergic transmission in the nucleus accumbens in response to the presentation of a cocaine-paired environment (Barr et al., 1983; Brown and Fibiger, 1992). The present results, together with the previous neurochemical data, strongly suggest that although the development of cocaine-induced environment-specific conditioning is dependent on the dopaminergic projection to the nucleus accumbens, the neurochemical events associated with the expression of the conditioned response are not. Taken as a whole, it appears that cocaine-induced environment-specific locomotion is not simply reflective of an increase in dopaminergic transmission to the nucleus accumbens, but is associated with increased neuronal activation within various forebrain limbic structures known to be critically involved in emotion and learning. Consequently, the results of the present study suggest that this specific form of conditioning involves similar neural circuits as other forms of learning (Mishkin and Aggleton, 1981).

\section{References}

Applegate CD, Frysinger RC, Kapp BS, Gallagher M (1982) Multiple unit activity recorded from the amygdala central nucleus during Pavlovian heart rate conditioning in rabbit. Brain Res 238:457-462.

Barr GA, Sharpless NS, Cooper S, Schiff SR (1983) Classical conditioning, decay and extinction of cocaine-induced hyperactivity and stereotypy. Life Sci 33:1341-1351.

Beninger RI, Hahn BL (1983) Pimozide blocks the establishment but not expression of amphetamine-produced environment-specific conditioning. Science 220:1304-1306.

Beninger RJ, Herz RS (1986) Pimozide blocks the establishment but not expression of cocaine-produced environment-specific conditioning. Life Sci 38:1425-1431.

Bentivoglio M, Balercia G, Kruger L (1990) The specificity of the nonspecific thalamus: the midline nuclei. In: Progress in brain research, Vol 85 (Uylings HBM, Van Eden CG, De Bruin JPC, Corner MA, Feenstra MGP, eds), pp 53-80. New York: Elsevier.

Björklund A, Lindvall O (1984) Dopamine-containing systems in the CNS. In: Handbook of chemical neuroanatomy, Vol 2, Classical neurotransmitters in the CNS (Björklund A, Hökfelt T, eds), pp 55-122. New York: Elsevier.

Brown EE, Fibiger HC (1992) Cocaine-induced conditioned locomotion: absence of increases in dopamine release. Neuroscience 48: 621-629.

Brown EE, Finlay JM, Wong JTF, Damsma G, Fibiger HC (1991) Behavioral and neurochemical interactions between cocaine and buprenorphine: implications for the pharmacotherapy of cocaine abuse. J Pharmacol Exp Ther 256:119-126.

Buchanan SL, Powell DA (1982) Cingulate cortex: its role in Pavlovian conditioning. J Comp Physiol Psychol 96:755-774.

Cador M, Robbins I'W, Everitt BJ (1989) Involvement of the amygdala in stimulus-reward associations: interactions with the ventral striatum. Neuroscience 30:77-86.

Campeau S, Hayward MD, Hope BT, Rosen JB, Nestler EJ, Davis M (1991) Induction of $c$-fos proto-oncogene in rat amygdala during unconditioned and conditioned fear. Brain Res 565:349-352.

Chastrette N, Pfaff DW, Gibbs RB (1991) Effects of daytime and nighttime stress on Fos-like immunoreactivity in the paraventricular nucleus of the hypothalamus, the habenula, and the posterior paraventricular nucleus of the thalamus. Brain Res 563:339-344.

Delfs JM, Schreiber L, Kelley AE (1990) Microinjection of cocaine into the nucleus accumbens elicits locomotor activation in the rat. J Neurosci 10:303-310.

Di Chiara G, Imperato A (1988) Drugs abused by humans preferentially increase synaptic dopamine concentrations in the mesolimbic system of freely moving rats. Proc Natl Acad Sci USA 85:5274-5278.

Dragunow M, Faull R (1989) The use of c-fos as a metabolic marker in neuronal pathway tracing. J Neurosci Methods 29:261-265.

Dragunow M, Robertson HA (1987) Kindling stimulation induces cfos protein(s) in granule cells of the rat dentate gyrus. Nature 329: $441-442$.

Dunn LT, Everitt BJ (1988) Double dissociations of the effects of amygdala and insular cortex lesions on conditioned taste aversions, passive avoidance, and neophobia in the rat using the excitotoxin ibotenic acid. Behav Neurosci 102:3-22.

Everitt BJ, Morris KA, O'Brien A, Robbins TW (1991) The basolateral amygdala-ventral striatal system and conditioned place preference: further evidence of limbic-striatal interactions underlying rewardrelated processes. Neuroscience $42: 1-18$.

Fibiger HC, Phillips AG (1987) Role of catecholamine transmitters in brain reward systems: implications for the neurobiology of affect. In: Brain reward systems and abuse (Engel J, Oreland L, eds), pp 6174. New York: Raven.

Finlay JM, Jakubovic A, Phillips AG, Fibiger HC (1988) Fentanyl- 
induced conditional place preference: lack of associated conditional neurochemical events. Psychopharmacology 96:534-540.

Fu L, Beckstead RM (1992) Cortical stimulation induces fos expression in striatal neurons. Neuroscience 46:329-334.

Gabriel M, Sparenborg E (1987) Posterior cingulate cortex lesions eliminate learning-related unit activity in the anterior cingulate cortex. Brain Res 409:151-157.

Gabriel M, Foster K, Orona E (1980) Interactions of laminae of the cingulate cortex with the anteroventral thalamus during behavioral learning. Science 203:1050-1052.

Gawin FH (1991) Cocaine addiction: psychology and neurophysiology. Science 251:1580-1586.

Graybiel AM, Moratalla R, Robertson HA (1990) Amphetamine and cocaine induce drug-specific activation of the $c$-fos gene in striosomematrix compartments and limbic subdivisions of the striatum. Proc Natl Acad Sci USA 87:6912-6916.

Groenewegen HJ (1988) Organization of the afferent connections of the mediodorsal thalamic nucleus in the rat, related to the mediodorsal-prefrontal topography. Neuroscience $24: 379-431$.

Groenewegen HJ, Berendse HW, Wolters JG, Lohman AHM (1990) The anatomical relationship of the prefrontal cortex with the striatopallidal system, the thalamus and the amygdala: evidence for a parallel organization. In: Progress in brain research, Vol 85 (Uylings HBM, Van Eden CG, De Bruin JPC, Corner MA, Feenstra MGP, eds), pp 95-118. New York: Elsevier

Hiroi N, White NM (1991) The lateral nucleus of the amygdala mediates expression of the amphetamine-produced conditioned place preference. I Neurosci 11:2107-2116.

Hunt SP, Pini A, Evan G (1987) Induction of c-fos-like protein in spinal cord neurons following sensory stimulation. Nature 328:632634.

Johanson CE, Fischman MW (1989) The pharmacology of cocaine related to its abuse. Pharmacol Rev 41:3-52.

Joyce EM, Koob GF (1981) Amphetamine-, scopolamine- and caffeine-induced locomotor activity following 6-hydroxydopamine lesions of the mesolimbic dopamine systems. Psycopharmacology 73: 311-313.

Kalivas PW, Duffy P (1990) The effects of acute and daily cocaine treatment on extracellular dopamine in the nucleus accumbens. Synapse 5:48-58.

Kapp BS, Gallager M, Frysinger RC, Applegate CD (1981) The amygdala, emotion and cardiovascular conditioning. In: Amygdaloid complex (Ben-Ari Y, ed), pp 355-366. Amsterdam: Elsevier.

Kelly PH, Seviour PW, Iversen SD (1975) Amphetamine and apomorphine responses in the rat following 6-OHD $\Lambda$ lesions of the nucleus accumbens septi and corpus striatum. Brain Res 94:507-522.

Krettek JE, Price JL (1978) Amygdaloid projections to subcortical struclures within the basal forebrain in the rat and cat. J Comp Neurol 178:225-254.

Lisoprawski A, Herve D, Blanc G, Glowinski J, Tassin JP (1980) Selective activation of the mesocortico-frontal dopaminergic neurons induced by lesions of the habenula in the rat. Brain Res 183:229234.

Lopez da Silva FH, Witter MP, Boeijinga PH, Lohman AHM (1990) Anatomic organization and physiology of the limbic cortex. Physiol Rev 70:453-511.

Lyness WH, Friedle NM, Moore KE (1979) Destruction of dopaminergic nerve terminals in nucleus accumbens: effects on $d$-amphetamine self-administration. Pharmacol Biochem Behav 11:553-556.

Mishkin M, Aggleton J (1981) Multiple functional contributions of the amygdala in the monkey. In: Amygdaloid complex (Ben-Ari Y, ed), pp 409-420. Amsterdam: Elsevier.

Möller H-G, Nowak K, Kuschinsky K (1987) Conditioning of preand post-synaptic behavioural responses to the dopamine receptor agonist apomorphine in rats. Psychopharmacology 91:50-55.

Moore RY, Card JP (1984) Noradrenaline-containing neuron systems. In: Handbook of chemical neuroanatomy, Vol 2, Classical neurotransmitters in the CNS (Björklund A, Hökfelt T, eds), pp 123-156. New York: Elsevier.

Morgan I, Curran T (1989) Stimulus-transcription coupling in neurons: role of cellular immediate-early genes. Trends Neurosci 12:459462.

Pascoe JP, Kapp BS (1985) Elcctrophysiological charactcristics of amygdaloid central nucleus during Pavlovian fear conditioning in the rabbit. Behav Brain Res 16:117-133.
Pettit HO, Justice JB Jr (1991) Effect of dose on cocaine self-administration behavior and dopamine levels in the nucleus accumbens. Brain Res 539:94-102.

Pettit HO, Ettenberg A, Bloom FE, Koob GF (1984) Destruction of the nucleus accumbens selectively attenuates cocaine but not heroin self-administration in rats. Psychopharmacology 54:167-173.

Phillipson OT, Pycock CJ (1982) Dopamine neurones of the ventral tegmentum project to both medial and lateral habenula. Exp Brain Res 45:89-94.

Post RM, Weiss SRB, Pert A (1988) Cocaine-induced behavioral sensitization and kindling: implications for the emergence of psychopathology and seizures. In: The mesocortical dopamine system, Vol 537 (Kalivas PW, Nemeroff CB, eds), pp 292-308. New York: New York Academy of Sciences.

Powell DA, Buchanan SL, Gibbs CM (1990) Role of the prefrontalthalamic axis in classical conditioning. In: Progress in brain research, Vol 85 (Uylings HBM, Van Eden CG, De Bruin JPC, Corner MA, Feenstra MGP, eds), pp 433-466. New York: Elsevier.

Raisman G (1966) The connexions of the septum. Brain 89:317-348.

Richelson E, Pfenning M (1984) Blockade by antidepressants and related compounds of biogenic amines uptake into rat brain synaptosomes: most antidepressants selectively block norepinephrine uptake. Eur J Pharmacol 104:277-286.

Ritz MC, Lamb RJ, Goldberg SR, Kuhar MJ (1987) Cocaine receptors on dopamine transporters are related to the self-administration of cocaine. Science 237:1219-1223.

Robbins TW, Cador M, Taylor JR, Everitt BJ (1989) Limbic-striatal interactions in reward-related process. Neurosci Biobehav Rev 13: 155-162.

Roberts DCS, Corcoran ME, Fibiger HC (1977) On the role of ascending catecholaminergic systems in intravenous self-administration of cocaine. Pharmacol Biochem Behav 6:615-620.

Roberts DCS, Koob GF, Klonoff P, Fibiger HC (1980) Extinction and recovery of cocaine self-administration following 6-hydroxydopamine lesions of the nucleus accumbens. Pharmacol Biochem Behav 12: 781-787.

Roberts DCS, Loh EH, Vickers G (1989) Self-administration of cocaine on a progressive ratio schedule in rats: dose-response relationship and effect of haloperidol pretreatment. Psychopharmacology 97: 535-538.

Robertson GS, Fibiger HC (1992) Neuroleptics increase c-fos expression in the forebrain: contrasting effects of haloperidol and clozapine. Neuroscience 46:315-328.

Robertson GS, Herrera DG, Dragunow M, Robertson HA (1989) LDopa activates c-fos in the striatum ipsilateral to a 6-hydroxydopamine lesion of the substantia nigra. Eur J Pharmacol 159:99-100.

Robertson GS, Pfaus JG, Atkinson LJ, Matsumara H, Phillips AG, Fibiger HC (1991) Sexual behavior increases c-fos expression in the forebrain of the male rat. Brain Res 564:352-357.

Roozendaal B, Oldenburger WP, Strubbe JH, Koolhass JM, Bohus B (1990) The central amygdala is involved in the conditioned but not the meal-induced cephalic insulin response in the rat. Neurosci Lett 116:210-215.

Rusak B, Robertson HA, Wisden W, Hunt SP (1990) Light pulses that shift rhythms induce gene expression in the suprachiasmatic nucleus. Science 248:1237-1240.

Sagar SM, Sharp FR, Curran T (1988) Expression of c-fos protein in brain: metabolic mapping at the cellular level. Science 240:13281331 .

Sharp FR, Sagar SM, Hicks K, Lowenstein D, Hisanaga K (1991) c-fos mRNA, Fos, and Fos-related antigen induction by hypertonic saline stress. J Neurosci 11:2321-2331.

Shu S, Ju G, Fan L (1988) The glucose oxidase-DAB-nickel method in peroxidase histochemistry of the nervous system. Neurosci Lett 85:169-171.

Steinbusch HWM (1984) Serotonin-immunoreactive neurons and their projections in the CNS. In: Handbook of chemical neuroanatomy, Vol 3, Classical transmitters and transmitter receptors in the CNS (Björklund A, Hökfelt T, Kuhar MJ, eds), pp 68-125. New York: Elsevier.

Stewart J, de Wit H, Eikelboom R (1984) Role of unconditioned and conditioned drug effects in the self-administration of opiates and stimulants. Psychol Rev 91:251-268.

Sutherland RJ (1982) The dorsal diencephalic conduction system: a 
review of the anatomy and functions of the habenular complex. Neurosci Biobehav Rev 6:1-13.

Swanson LW, Cowan WM (1979) The connections of the septal region in the rat. J Comp Neurol 186:621-656.

Tatum AL, Seevers MH (1929) Experimental cocaine addiction. J Pharmacol Exp Ther 36:401-410.

Thomas E (1988) Forebrain mechanisms in the relief of fear: the role of the lateral septum. Psychobiology 16:36-44.

Thomas E, Yadin E (1980) Multiple unit activity in the septum during Pavlovian aversive conditioning: evidence for an inhibitory role of the septum. Exp Neurol 69:50-60.

Thomas E, Yadin E, Strickland CE (1991) Septal unit activity during classical conditioning: a regional comparison. Brain Res 547:303308.
Walter S, Kuschinsky K (1989) Conditioning of morphine-induced locomotor activity and stereotyped behaviour in rats. J Neural Transm 78:231-247.

Weiss SRB, Post RM, Pert A, Woodland R, Murman D (1989) Context-dependent cocaine sensitization: differential effect of haloperidol on development versus expression. Pharmacol Biochem Behav 34: 655-661.

Young ST, Porrino LJT, Porrino LJ, Iadarola, MJ (1991) Cocaine induces striatal $\mathbf{c}$-fos-immunoreactivity proteins via dopaminergic D1 receptors. Proc Natl Acad Sci USA 88:1291-1295. 